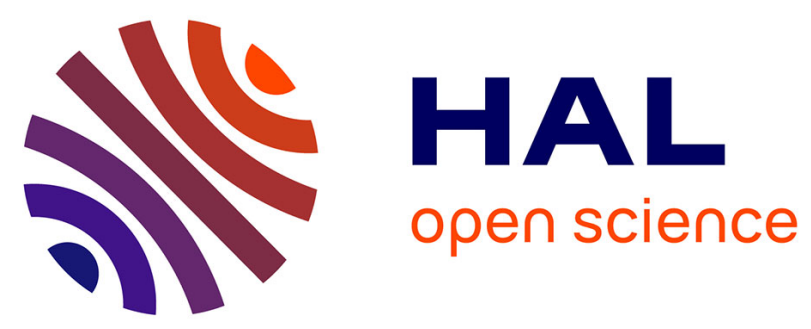

\title{
MATHEMATICAL SIMULATION OF X-RAY OPTICAL SYSTEMS USING MONTE CARLO METHOD
}

\author{
V. Nikolaev, R. Plotnikov, O. Marenkov, T. Singarieva
}

\section{- To cite this version:}

V. Nikolaev, R. Plotnikov, O. Marenkov, T. Singarieva. MATHEMATICAL SIMULATION OF XRAY OPTICAL SYSTEMS USING MONTE CARLO METHOD. Journal de Physique Colloques, 1984, 45 (C2), pp.C2-161-C2-164. 10.1051/jphyscol:1984236 . jpa-00223949

HAL Id: jpa-00223949

https://hal.science/jpa-00223949

Submitted on 1 Jan 1984

HAL is a multi-disciplinary open access archive for the deposit and dissemination of scientific research documents, whether they are published or not. The documents may come from teaching and research institutions in France or abroad, or from public or private research centers.
L'archive ouverte pluridisciplinaire $\mathbf{H A L}$, est destinée au dépôt et à la diffusion de documents scientifiques de niveau recherche, publiés ou non, émanant des établissements d'enseignement et de recherche français ou étrangers, des laboratoires publics ou privés. 
JOURNAL DE PHYSIQUE

Colloque C2, supplément au n², Tome 45, février 1984

page C2-161

MATHEMATICAL SIMULATION OF X-RAY OPTICAL SYSTEMS USING MONTE CARLO METHOD

\author{
V.P. Nikolaev, R.I. Plotnikov, O.S. Marenkov and T.V. Singarieva \\ VNIINauchprybor, Leningrad, U.S.S.R.
}

Résumë - On a effectué une simulation mathématique des systèmes $\bar{d}$ 'optique des rayons $x$ à cristaux à double courbure. On a montré que les courbes de rendement de réflexion des cristaux à double courbure pour le cas d'une source ponctuelle possèdent deux maxima : $R_{2} / R_{1}=1$ (sphère) et $R_{2} / R_{1}=\sin ^{2} \theta_{Q}$ (surface en

forme de tonneau à focalisation ponctuelle). Des cristaux sphériques sont recommandés pour des montages de rayons $\mathrm{X}$ à fentes (diaphragmes).

\begin{abstract}
There is performed mathematical simulation of X-ray optical systems with double-bent crystals. It is show that curves of reflection efficiency for double-bent crystals have two maxime at $R_{2} / R_{1}=1$ (sphere) and $R_{2} / R_{1}=\sin ^{2} \theta_{0}$ (barrel-shaped surface with point focusing) when using a point radiation source. For $X$-ray optical systems with slit sources (diaphragms) it is advisable to use spherical crystals.
\end{abstract}

To compute parameters of complex X-ray optical systems (efficiency, resolution, aberrations, tolerences for menufacture and arrangement of system components and so on) we applied a technique of mathematical simulation by Monte Carlo method $/ 1,2 /$. The developed technique was used for computation of X-ray optical systems with double-bent crystals which are of high interest in development of X-ray spectrometers of high efficiency $/ 3,4 /$. In the present work there was studied distribution of reflecting areas and reflection efficiency for crystals bent along surfaces created by rotation of an arc of radius $R_{1}$ lying in a focal plane around an axis lying in the same plane. In this case a central point of the arc has rotation radius $\mathrm{R}_{2}$. It was assumed that reflecting planes of the crystal are paralIel to its surface.

When trajectory of a photon is assigned as a straight line passing via the point radiation source and current point on the crystal surface, a glancing angle $\theta$ complementary to the angle between photon trajectory and normal to the crystal surface in the current point may be found. For those points on the surface under study which are located at rendom or as a net there was computed angle $\theta$ and determined difference between this angle and Bragg angle $\theta_{0}$. As a result of computation there was obtained a net listing (topogram) with symbols of three types of points corresponding to the following cases:

$$
\left(\theta-\theta_{0}\right)>\delta / 2, \delta / 2=\left(\theta-\theta_{0}\right)>-\delta / 2, \quad\left(\theta-\theta_{0}\right)<-\delta / 2
$$

where $\delta$ is a crystal mosaic. The second case corresponds to ref- 
lection. Then there was computed a value of solid angle $\Omega$ at which a reflecting area is seen from the source (reflection efficiency). In Fig. 1 there is shown succession of topograms for various values of $\xi=R_{2} / R_{1}$. Reflecting areas of the surface are black, areas with value 0 corresponding to the first case are marked by sign " - " and those corresponding to the third case are marked by " + ".

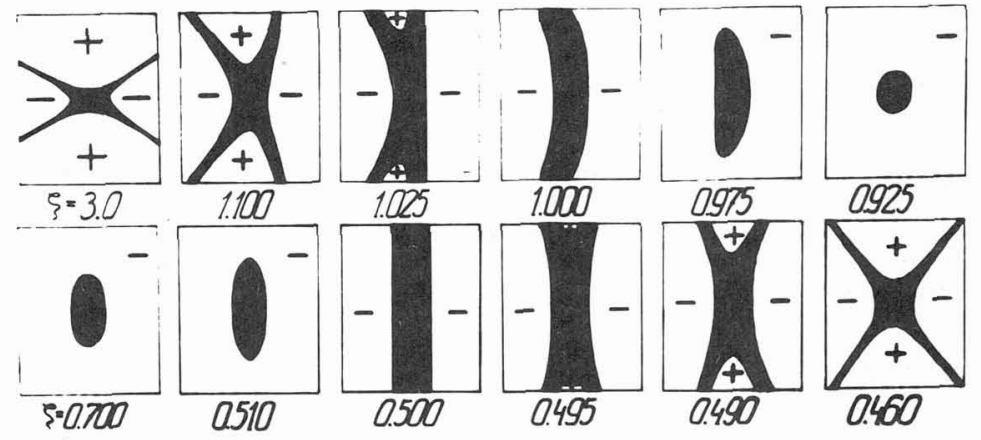

Fig. 1 - Topograms of crystal surface ( height $h / R_{1}=0.4$, width $\mathrm{b} / \mathrm{R}_{1}=0.2$ ) for different values of $\xi=\mathrm{R}_{2} / \mathrm{R}_{1}$ with $0_{0}=45^{\circ}, \delta=$ 0.00058 . Source is located in focal plane.

As it is seen from the figure for large values of $\xi$ the topograms correspond to Iohann focusing. As the surface shape approximates to a sphere a cross is transformed in a slightly bent vertical belt. Then with decrease of $\xi$ this belt is compressed in an elliptical spot which is again extended along the vertical changing at $\xi=$ $0.5 \operatorname{Sin}^{2} 45^{\circ}$ into a straight closed vertical belt corresponding to the condition of point focusing at the barrel-shaped surface $/ 4 /$. With the further decrease of $\xi$ a cross similar to the initial one appears again. It may be shown analytically that the height of reflecting area in the center of crystal has two maxima ( at $\xi=1$ and

$\xi=\sin ^{2} \mathrm{O}_{0}$ ) corresponding to the crystal bending along the sphere and barrel-shaped surface with point focusing (Fig. 2).

When the reflecting surface is obtained by rotation of logarithmic spiral arc or the crystal is made according to Iohansson the abovementioned dependence is a characteristic of reflecting area height of the whole crystal, i.e. of its efficiency. Reflection efficiency as a function of for the case shown in Fig. 1 is represented in Fig. 3. As it is seen from Fig. 3 there are 2 typical maxima of reflection located near to $\xi=1$ and $\xi=0.5$. The latter maximum is narrow enough and so there are high requirements to the accuracy of $R_{2}$. Requirements to the accuracy of $R_{2}$ when bending along the sphere are considerably lower. Similar computations for other values of $\theta_{0}$ show that the general behaviour of reflection efficiency curves is reserved ( maxima are near to $\xi=1$ and $\xi=\operatorname{Sin}^{2} \theta_{0}$ ), these maxima are sharpened with the decrease of $\theta_{0}$

In Fig. 4 there are shown crystal surface topograms in case of source displacement along a normal to the focal plane for values $=0.5$ and $\xi=1$. Correspording curves of reflection efficiency are show 


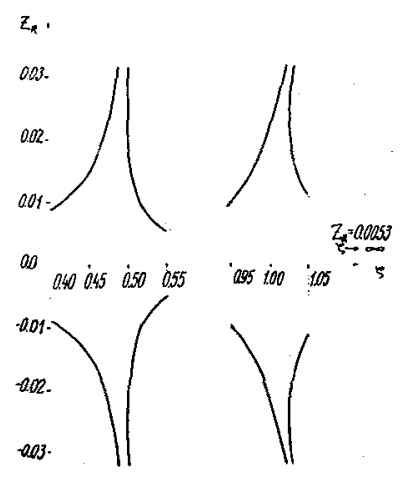

Fig. 2 - Reflecting area height $z_{R}=z / R$ (in direction of noxmal to focal plane) as a function of $\xi$ for conditions shown in Fig. 1 .

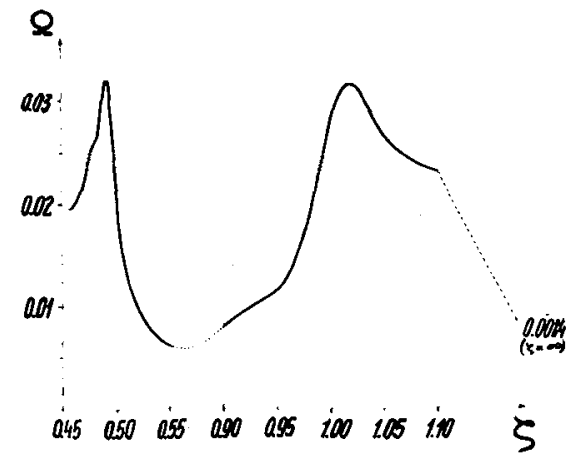

Fig. 3 - Reflection efficiency $\Omega$ as a function of $\xi$ for conditions shown in Fig. 1.

in Fig. 5. As it is seen from Figs.4 and 5 arrangements with crystals bent along the barrel-shaped surface with point focusing are extremely critical to displacement of the point source along the normal to the focal plane that hampers the use of slit sources. Unlike this case for the systems with spherically bent crystals it is possible and advisable to use slit sources. Computations for other values of $\theta_{0}$ confirm these conclusions. 


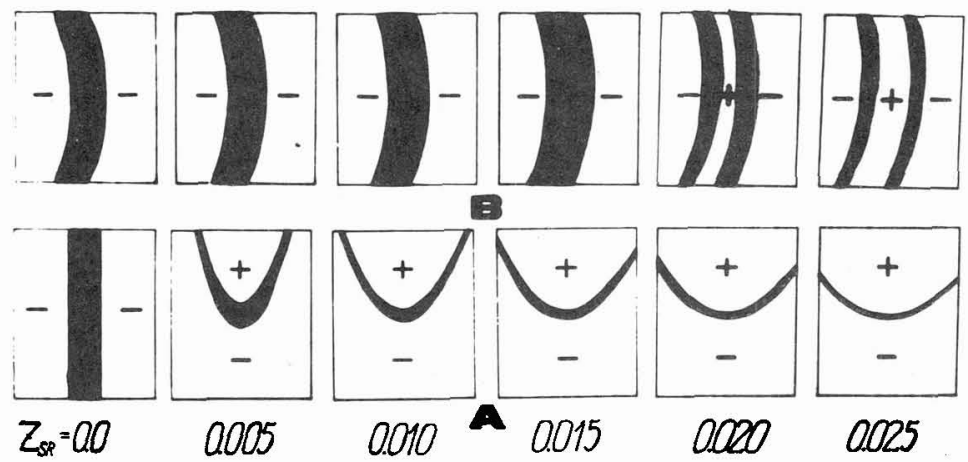

Fig. 4 - Surface topograms of the same crystal for various displacements of the source $\left(Z_{S R}=Z_{S} / R_{1}\right)$ along normal to focal plane with $\xi=0.5$ (A) and $\xi=1$ (B).

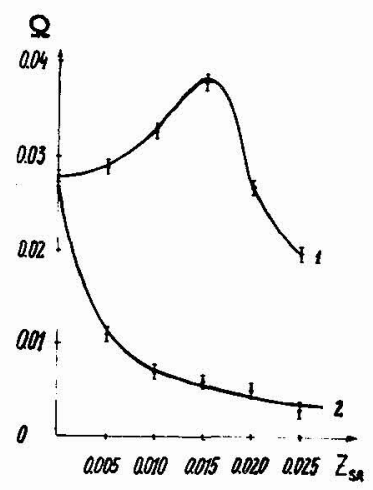

Fig. 5 - Reflection efficiency of the same crystal as a function of $\mathrm{z}_{\mathrm{SR}}$ with $\xi=1$ (1) and $\xi=0.5$ (2).

\section{References}

1. PLOTNIKOV R.I. et al., Apparatura 1 metody rentgenovskogo analiza 23 (1980) 27 .

2. PLOMNIKOV R.I. et al., Apparatura i metody rentgenovskogo analiza 28 (1982) 42 .

3. EGGS J.J., Z. angew. Phys. 20 No.2 (1965) 118.

4. BERREMAN D.W. et al., Rev. Sci. Instr. 25 (1951) 1219. 